Article

\title{
Improvement of Wind Energy Production through HVDC Systems
}

\author{
Morris Brenna, Federica Foiadelli, Michela Longo * and Dario Zaninelli \\ Department of Energy, Politecnico di Milano, Via La Masa, 34-20156 Milano (MI), Italy; \\ morris.brenna@polimi.it (M.B.); federica.foiadelli@polimi.it (F.F.); dario.zaninelli@polimi.it (D.Z.) \\ * Correspondence: michela.longo@polimi.it; Tel.: +39-02-2399-3759
}

Academic Editors: Pierluigi Siano and Miadreza Shafie-khah

Received: 26 October 2016; Accepted: 10 January 2017; Published: 27 January 2017

\begin{abstract}
Variable and non-programmable resources, such as solar and wind, have undergone a stunning growth in recent years and are likely to gain even more importance in the future. Their strong presence in the national electricity mix has created issues in many countries regarding the secure operation of the power system. In order to guarantee the stability of the system, several TSOs have resorted to wind energy curtailment, which represents a waste of clean energy and an economic loss. In order to analyze this issue, a model of the Italian power system was developed, a program able to simulate the electricity dispatching mechanism. The model was, then, used to evaluate possible solutions to reduce wind curtailment. In particular, a proposal for the construction of an HVDC line linking Southern and Northern Italy was studied.
\end{abstract}

Keywords: renewables integration; wind curtailment; Italian power system; HVDC transmission system

\section{Introduction}

The search for clean and politically stable energy resources has lead in recent decades to the rather fast development of RES (Renewable Energy Sources) [1]. In the electricity production sector, solar and wind technologies have experienced an incredible growth and are projected to grow even more in the future [2,3]. PV and wind are, however, variable and non-programmable sources of energy, since their production relies on weather conditions that are inherently unstable [4,5]. This poses a problem for the operation of the electric system, where injections and withdrawals of electricity have to be balanced at any instant of time. When a secure balancing is not feasible or other constraints arise, System Operators are forced to curtail RES generation. This wastes clean and free energy, producing not only environmental but also economic damage. Indeed, when conventional power plants reduce their power output, they also cut their variable costs, dominated by fuel expenses. Curtailment for RES, instead, is particularly detrimental, since they have almost zero variable costs [6]. Restriction so far has mostly involved wind generation, for it is the most widespread non-programmable resource worldwide, it is less predictable than PV and it is generally located in remote areas. Wind curtailment is determined by two main causes: transmission constraints and grid stability issues [7-9].

Transmission constraints are typically produced by local congestions that arise from the delayed development of grid infrastructures. Indeed, the expansion of wind plants has been fast and generally not suitably followed by network reinforcements. These are particularly necessary, for wind farms have spread mainly in remote areas, where loads are low and the grid is quite weak. Where the existing connections are not able to accommodate all the energy produced from wind power plants, the latter have to be shut down to avoid lines' overload $[10,11]$. As concerns grid stability, the issue arises from the fact that a certain level of minimum conventional generation always has to be guaranteed, in order to provide the necessary ancillary services or for technical constraints of the working power 
plants [12-14]. When the sum of minimum conventional generation and RES production exceeds the load, then wind energy has to be curtailed in order to maintain the system balance. RES, indeed, have until recently been exempted from the provision of ancillary services, such as frequency and voltage regulation. Besides, the high penetration of variable resources in the electricity mix has increased the amount of reserve margins that conventional power plants have to set aside to support the network. Some ancillary services have now also responsibility for, renewable resources, including low- and high-voltage-ride-through, insensitivity to frequency oscillations (in a specific range), reactive power control and frequency regulation (typically only during over-frequency events) [15-17]. A discussion is still ongoing about whether to include RES in the under-frequency regulation obligation. This would penalize them economically (as they should operate at a reduced power level for most of the time) but would allow an easier integration of renewables and, as a consequence, higher penetration percentages in the electricity mix.

As part of the European Union, Italy has embarked on a sustainability roadmap involving the energy sector, aimed at tackling global warming and ensuring security of supply-two objectives that go concurrently in the direction of a greener energy mix. According to the Directive 2009/28/EC of the European Parliament [18], commonly referred to as the 20-20-20 targets, the following objectives have to be fulfilled in the year 2020 by the EU as a whole: a $20 \%$ reduction in the GHG emissions with respect to the 1990 level; a $20 \%$ reduction in primary energy consumption compared to BAU, by means of increased energy efficiency and a $20 \%$ share of renewables in the energy mix, with the additional constraint of a $10 \%$ share of biofuels in the transportation sector. The latter target is directly connected to the development of RES in the European Union. It is achieved by imposing specific national objectives to each Member State, which, in turn, is in charge of drawing up national plans to fulfill such requirement. This encompasses the three main sectors of energy consumption: heating (RES-H), transportation (RES-T) and electricity (RES-E) — with only the latter being of interest in the discussion about renewables' curtailment.

The huge development of wind and PV, in particular, requires an accurate analysis. Indeed, a big penetration of such resources, which are variable and unpredictable, has posed the question of how to securely integrate them in the electric system, where injections and withdrawals of electricity have to be balanced at any instant of time. When this cannot be done without hitting constraints on transmission capacity or on provision of ancillary services, wind and/or solar resources need to be curtailed. RES curtailment, wastes free and clean energy, thus leading to an economic loss and to an increase in GHG and polluting emissions $[19,20]$.

This work is aimed at analyzing the problem of RES curtailment, with a particular focus on wind, which, so far, has been the main resource affected by this issue. A description of the problem, with its causes and current implications in some countries and, with particular attention, in Italy, is followed by a detailed study of the Italian case. This includes modeling the Italian electric system on the software PLEXOS by Energy Exemplar and checking how a suitable network expansion might mitigate wind curtailment in the country. In particular, the creation of a HVDC line connecting Southern and Northern Italy is conceived and simulated [21,22]. The choice of Direct Current comes not only from the great distance to be covered by the line, but also from its better controllability and its capability to link systems that have different phases or frequencies (even temporarily). These characteristics make HVDC a particularly suitable choice in a network more and more dominated by the presence of variable and non-programmable RES [23,24].

\section{Problem Description}

The great development undergone by RES such as wind and solar in the recent decades has significantly affected the operation of the electric power system. Wind and solar are, indeed, non-predictable and non-programmable energy sources, since they rely on natural resources that are intrinsically intermittent and affected by local weather conditions. Due to these characteristics, when wind and solar are present with high penetration levels, technical and operational issues may 
arise that limit their full exploitation. In such cases, their power is curtailed and their production lost, thus leading to economic damage for the producer.

Indeed, the power produced from RES plants comes for free, since no fuel is needed and the operational costs (except for the variable operation and maintenance costs) are zero. However, plant operation-and, consequently, electricity sale-is needed by the plant owner to recover its initial investment. Therefore, when wind or solar energy is curtailed, the levelized cost to produce an energy unit increases. In fact, the levelized cost of energy is defined as the sum of the levelized fixed costs and the levelized variable costs. The latter are negligible in a RES plant, while the former can be expressed in Equation (1):

$$
\operatorname{LCOE}\left[\frac{\$}{\mathrm{MWh}}\right]=\frac{\text { Capital cost } \times F C R+\text { Fixed } O \& M}{C F \times 8760}
$$

where $F C R$ is the Fixed Charge Rate and $C F$ is the capacity factor. Since renewable curtailment reduces the utilization of the plant, its capacity factor is decreased, thereby increasing the overall levelized cost of energy [25]. Nevertheless, some constraints might arise in the system in certain situations, impeding the employment of such a strategy and, thus, forcing the curtailment of wind and solar power. Two main restrictions are accountable for the necessity of wind and solar energy curtailment at a certain time. The first is a local constraint on transmission lines, which, due to their limited capacity, may not be able to transport the whole power produced by the plants. The second restriction is related to the need of maintaining the system stability, by matching generation to demand at any instant of time.

Since RES plants, and in particular wind, are typically installed in remote areas, they need dedicated transmission lines to transport the power produced to the load centers. In some cases, these lines result in being inadequate to accommodate the whole wind power production, thereby requiring a curtailment of the upstream generation. The main reason behind this limit is usually the delay between transmission lines and power plant construction times [26]. Indeed, upgrades of the transmission system might take longer times, thus limiting the amount of power successfully delivered from the wind plant to the grid. Besides phenomena of local congestion occurring at the connection with the grid, other transmission constraints might arise from a non-homogeneous geographical distribution of RES plants and load centers. Indeed, renewables being produced in remote areas or in parts of the country characterized by lower electricity demand might need to transport their generated power to regions or centers with higher load levels. The main source of system flexibility is the presence of conventional power plants that are able to provide upward and downward reserves very rapidly, so as to maintain the system balance between generation and demand in spite of the renewables' variability. These plants are usually fossil-fuel-based, such as open-cycle gas turbines. Additional sources of flexibility may come from the use of storage systems, the employment of Demand Side Management (DSM) strategies, and the development of grids' interconnections [27]. Moreover, a certain level of conventional generation always needs to be guaranteed. Such Minimum Conventional Generation (MCG) may derive from technical, operating or other constraints. It has to be noted that minimum operating levels for the thermoelectric generation tend to increase with renewables penetration itself, since a stronger presence of intermittent non-predictable energy sources requires a greater capability of the system to provide rapid increase or decrease of the overall production. Therefore, wind and solar production is curtailed when it exceeds not just the total load but the difference between the load and the MCG [28]. This situation is shown graphically in Figure 1. 


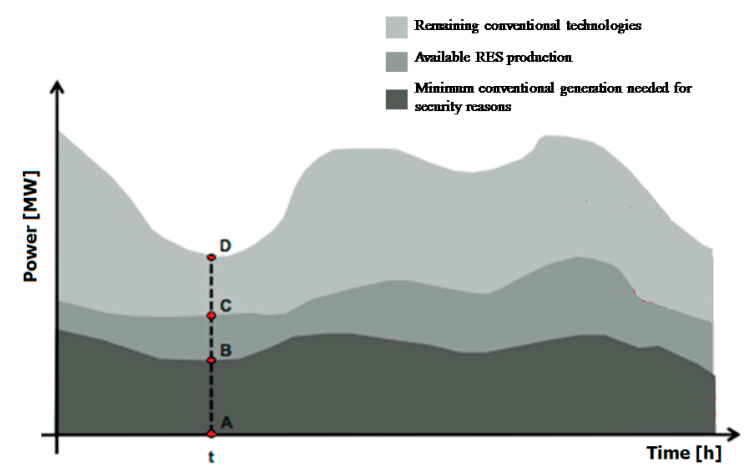

(a)

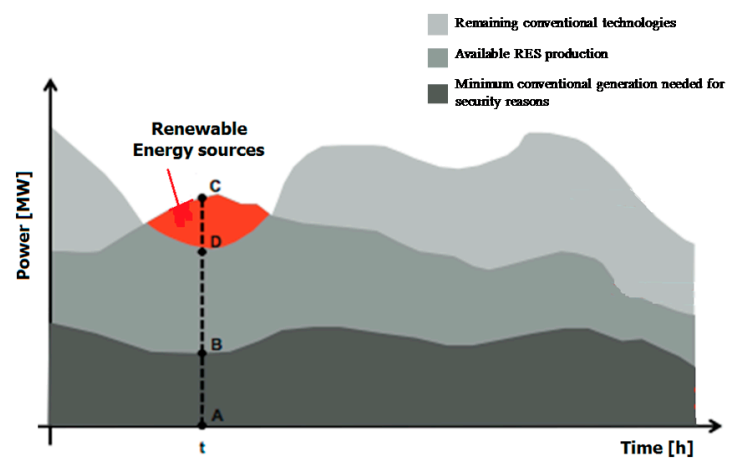

(b)

Figure 1. (a) Load profile and generation distribution in case of "normal" operation; (b) Load profile and generation distribution with RES curtailment requirements [28].

\section{Modelization of the System}

In order to evaluate the effect of network interventions on wind curtailment, a model of the Italian electric system was built [29]. For this purpose, the software PLEXOS Integrated Energy Model by Energy Exemplar was used [30] (Figure 2).

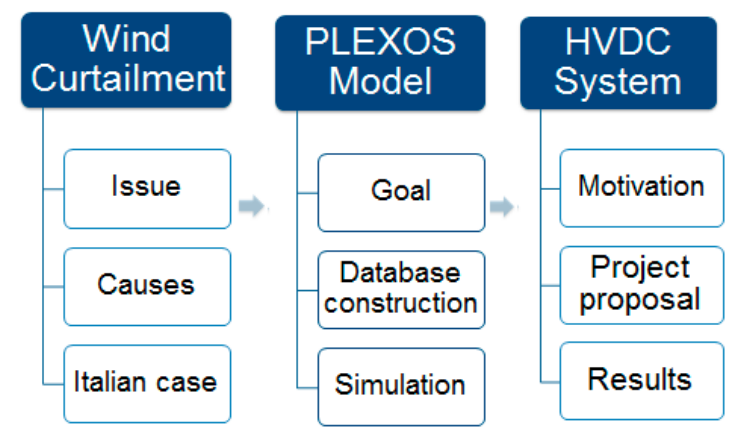

Figure 2. Outline of the problem.

The Italian system is divided into the six geographical zones defined: NORD, CNORD, CSUD, SUD, SICI, and SARD [31]. The poles of limited production are grouped with the corresponding zones. Indeed, the model is focused on wind curtailment related to stability issues, neglecting that caused by local transmission constraints. The latter, which was predominant in the past and has been progressively reduced in the last years, can only be solved by improving the adequacy of local connections. Therefore, the goal is to investigate solutions able to guarantee system adequacy while reducing wind curtailment occurrence and associated costs.

\subsection{Network Topology}

The network topology is identified in PLEXOS by defining regions, nodes, and lines. The regions are the main transmission areas. They define the system control areas and can be associated with load values for the area they represent and to reserve requirements. They can contain one or more nodes. Nodes represent transmission buses, i.e., single network elements, connected one to the other by means of transmission lines. They are associated with the generators contained in the area they embody and to the load expected for that area. The model developed for this study considers a simplified version of the network, with the attention focused on inter-zonal power exchanges and not on local network configuration. According to this choice, the regions and nodes defined are the ones shown in Figure 3. 


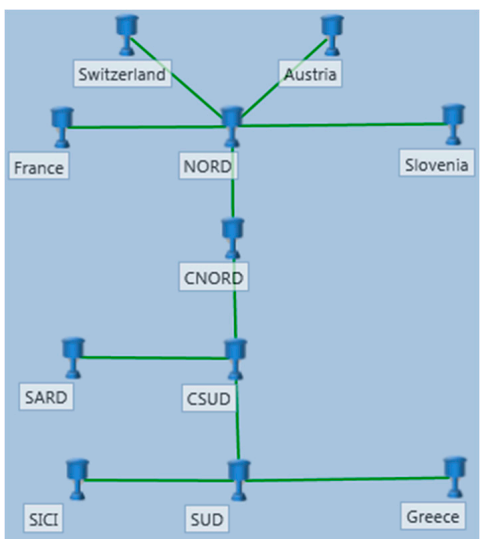

Figure 3. Network configuration.

\subsection{Generation and Load}

PLEXOS allows the definition of "Generators" objects. These are identified by a name and can be grouped in Categories (e.g., according to their type, they can be subdivided into coal power plants, CCGT, etc.). Each generator needs to be associated with the node where it injects its electricity production. Besides, generators are identified by the number of producing units, their maximum capacity (i.e., rated power) and their minimum stable level. During the simulation, according to the economic dispatch strategy, there is assigned hourly to each generator a certain power level, comprised between the minimum stable level of one unit and the maximum capacity of the plant (considering all units working together). Additional properties can be assigned to generators to better model their characteristics-and, therefore, identify the type of generator considered. These are, among others, fuel price (\$/GJ), heat rate (GJ/MWh), run-up rate at start-up ( $\mathrm{MW} / \mathrm{min})$, maximum ramp-up and ramp-down rates $(\mathrm{MW} / \mathrm{min})$, ramp-up and ramp-down charges $(\$ / \mathrm{MW})$, maximum and minimum capacity factor per year $(\%)$, reserve share $(\%)$, maintenance rate $(\%)$, forced outage rate $(\%)$, mean time for repairs (hours) and others.

Renewable energy sources such as wind, PV, and hydro run-of-river are characterized by a variability that cannot be predicted in advance. For this reason, their rated power is just a reference maximum producible value, but the actual power level is determined by the resource availability. The best way to describe this behavior on PLEXOS is by defining the generator's "Rating" property. Rating defines the generator capacity profile based on a data file uploaded by the user.

Hourly capacity values (\%) can be entered in this field to define the hourly capacity of each generator, resulting from the actual resource availability data. Such yearly production profiles were included in the dataset provided by UCC.

Renewable sources enter the market at zero-price offers. This grants them priority of dispatch with respect to conventional power sources.

The overall values of installed capacity in each zone, updated to year 2014, are summarized in Table 1.

Table 1. Installed capacity (MW) as of 2014.

\begin{tabular}{ccccccc}
\hline RES & NORD & CNORD & CSUD & SUD & SICI & SARD \\
\hline Hydro & 16,083 & 1090 & 2714 & 878 & 719 & 460 \\
Wind & 110 & 124 & 1512 & 4072 & 1750 & 993 \\
PV & 7996 & 2208 & 2599 & 3655 & 1256 & 705 \\
Geothermal & 0 & 773 & 0 & 0 & 0 & 0 \\
Biomass & 2496 & 281 & 475 & 613 & 80 & 89 \\
CCGT & 22,014 & 1831 & 5964 & 9594 & 2392 & 0 \\
Coal & 2514 & 150 & 1980 & 3280 & 0 & 1339 \\
Oil/Gas & 3300 & 656 & 3664 & 334 & 1783 & 551 \\
\hline
\end{tabular}


Conventional plants, such as coal, CCGT and OCGT ones, are entered individually in the model, with data corresponding to each plant currently operating on the network. Average properties for each category of power plant are considered. Table 2 shows the main assumptions considered [32].

Table 2. Average properties of conventional power plants [32].

\begin{tabular}{cccccc}
\hline $\begin{array}{c}\text { Conventional } \\
\text { Plants }\end{array}$ & $\begin{array}{c}\text { Maintenance } \\
\text { Rate (\%) }\end{array}$ & $\begin{array}{c}\text { Forced Outage } \\
\text { Rate (\%) }\end{array}$ & $\begin{array}{c}\text { Min Stable } \\
\text { Level (\%) }\end{array}$ & $\begin{array}{c}\text { Ramp Up Rate } \\
\text { (\%min) }\end{array}$ & $\begin{array}{c}\text { Run Up Rate } \\
\text { (\%min) }\end{array}$ \\
\hline CCGT & 6 & 4 & 50 & 5 & 2.5 \\
Coal & 10 & 6 & 40 & 2 & 1 \\
Oil/Gas & 5 & 3 & 50 & 8.33 & 22.2 \\
Nuclear & 6 & 4 & 50 & 5 & 5 \\
\hline
\end{tabular}

Fuel consumption in thermal plants is described by means of their heat rate [32] and each fuel is associated with the corresponding price [33]. Fuel prices assumed are: natural gas equal to $6.16 € / \mathrm{GJ}$; coal equal to $3.32 € / G$ J and uranium equal to $0.156 € / G J$.

Other variable expenses and components that enter in the evaluation of the producers' offer bids are added. Heat rates and variable costs are differentiated by plants considering that, in general, the efficiency of turbomachines increases with the size, while the specific non-fuel costs (e.g., O\&M) decrease. Biomass and geothermal plants are not completely dispatchable, since their production is limited mainly by fuel availability and maintenance. Similarly, hydro plants with reservoir have been associated with a maximum producible monthly energy, derived from actual production data [34]. This also takes into consideration the yearly rainfall pattern in Italy, which on average is higher during spring and summer.

The other renewable energy sources (wind, PV, and hydro run-of-river) are characterized by a variability that cannot be predicted in advance. For this reason, their rated power is just a reference maximum producible value, but the actual power level is determined by the resource availability. For wind and run-of-river profiles, whose shape is not regular over time, also an auto-correlated noise was added in order to introduce a stochastic component to the resource. Renewable sources (except for hydro with reservoir) enter the market with zero-price offers. This grants them priority of dispatch with respect to the conventional power sources. Wind generators, instead, although characterized by priority of dispatch, which is granted by their zero-price bids, are allowed to be curtailed when no other actions on conventional generators are possible.

Load values are defined as properties of nodes or regions. In this model, each node is associated with a spreadsheet file containing the hourly values of load for each hour of the year. The values found are summarized in Table 3.

Table 3. Annual consumption and peak load values in the six Italian zones.

\begin{tabular}{ccccccc}
\hline Values & NORD & CNORD & CSUD & SUD & SICI & SARD \\
\hline Annual load (GWh) & 156,527 & 25,871 & 40,644 & 25,972 & 18,049 & 11,416 \\
Peak load (MW) & 27,394 & 5508 & 8243 & 4491 & 3032 & 2104 \\
\hline
\end{tabular}

\subsection{Trasmission}

The "Line" objects in PLEXOS connect two nodes together and allow exchanges of power between them. They are identified by their name and by the exporting ("Node from") and importing ("Node to") nodes. They are bidirectional, allowing both a positive flow (in the direction "Node from"--Node to") and a negative flow (in the direction "Node to-Node from"). Limits on interconnection capacity are set by defining the properties "Max flow" and "Min flow", which represent the line power ratings in the positive and negative direction, respectively (with "Min flow" being a negative number). Alternatively, lines can be defined as unidirectional by setting the "Min flow" property to zero. 
Such properties can also be time-variant assuming, for example, different values depending on the seasons (they typically have lower capacity in summer) or on-peak/off-peak conditions. The properties "Resistance" and "Reactance" of the lines can also be defined. The values need to be entered in per-unit, considering a reference base power of 100 MVA. If the reactance is not defined, the line is automatically treated as a DC link.

The interconnection capacities used in the simulation were obtained from the European Network of Transmission System Operators for Electricity's (ENTSO-E) 2016 Ten Year Network Development Plan (TYNDP).

In the PLEXOS model the total interconnection capacity in operation between countries is represented as a single Line object, even though the reference interconnection capacities are equal to the sum of all AC and DC lines crossing national borders.

Except for the HVDC line linking CSUD and SARD, all the connections are in AC, hence their impedance has to be considered. High-voltage lines usually present a reactance-to-resistance ratio of about 10. For such reason, the resistance of the lines is considered negligible, while the reactance has to be included in the model. The latter was evaluated by analyzing the transmission lines connecting the various zones and estimating the distance covered; an average value of $0.8 \mathrm{mH} / \mathrm{km}$ was assumed. The values of reactance relevant to the inter-zonal connections are shown in Table 4, expressed in per unit.

Table 4. Reactance (p.u.) of the inter-zonal connections.

\begin{tabular}{cc}
\hline Zone & Reactance (p.u.) \\
\hline CNORD-CSUD & 0.01866 \\
CNORD-NORD & 0.01196 \\
SICI-SUD & 0.009182 \\
SUD-CSUD & 0.01486 \\
\hline
\end{tabular}

\subsection{Imports and Exports}

Since the electricity provision in Italy relies extensively on imports, it is fundamental to model also the exchanges with the neighboring countries. In order to do this, five additional nodes were added to the system: France, Austria, Switzerland, Slovenia, and Greece. These are all connected to the NORD zone, except Greece, which is linked through a HVDC line to the SUD node [35,36]. The installed capacity in all regions considered was evaluated, together with their properties. Renewable energy profiles were defined based on data provided by the relevant TSOs or inferred based on meteorological similarities with Italian zones, when such data was not available. The national load profiles as well were derived from data obtained from the TSOs' webpages. The values of maximum interconnection capacity may vary seasonally and over time depending on the operational conditions. Besides, the values of reactance were derived with the same method used for the internal connections (Table 5).

Table 5. Reactance (p.u.) of the interconnections with neighboring countries.

\begin{tabular}{cc}
\hline Countries & Reactance (p.u.) \\
\hline Austria-NORD & 0.04109 \\
France-NORD & 0.01422 \\
Slovenia-NORD & 0.02434 \\
Switzerland-NORD & 0.01024 \\
\hline
\end{tabular}

\subsection{Ancillary Services}

In order for the model to mimic the real operation of the system, the reserve margins that conventional power plants operators set aside for ancillary services provision have to take into account. This is modeled by including both mandatory reserve bands for frequency regulation and balancing reserve requirements. In general, in Italy such a reserve band must equal 1.5\% of the plant's maximum 
capacity; however, a 10\% reserve margin is mandated in Sardinia and Sicily: indeed, the former is connected asynchronously with the continent, while the latter, although featuring an AC connection to Southern Italy, is peripheral with respect to the interconnected system and has limited exchange capability (and limited connection reliability, as well). ENTSO-E requires Italy to provide overall a minimum reserve band of $321 \mathrm{MW}$ for primary regulation. The dispatch of power plants' generation, hence, is constrained by the requirement that all reserve margins made available by the operating plants sum up to $321 \mathrm{MW}$ in each time interval (here, one hour). For the reasons previously mentioned, Sicily and Sardinia reserves are modeled separately, thus implying that they need to meet a certain reserve requirement by themselves, without relying on imports/exports with the continent. Balancing reserves are required to cope with generation or load imbalances. Differently from what is done for regulation reserves, each zone is modeled separately, since balancing reserves have to be provided at a local level. The provision is not mandatory but assigned based on the results of the ancillary services market. For this reason, the model does not associate any minimum provision requirement to the generators. However, the total amount of reserve available in each time interval has to be greater or equal than the Dynamic Risk. For upward reserves the Dynamic Risk is evaluated as the maximum between the power associated to generators' contingencies (the biggest units in the control areas are considered), importing lines contingencies, and load imbalances (a 10\% load forecast inaccuracy is here considered). Indeed, generation or import losses, together with eventual load forecast mismatches, require the deployment of upward spinning reserves or of fast-starting power plants. As concerns downward reserves, the Dynamic Risk is calculated as the maximum between the MW of exporting line contingencies and load imbalances. In fact, the failure of a line operated in the exporting direction or errors in the prediction of the load profile require online plants to reduce their power output, in order to maintain the stability of the system. An additional contribution from balancing reserves is needed to cope with the variability of intermittent generation, such as solar and wind. Indeed, more reserves are needed when large volumes of generation from RES are present in the system. The additional margins guarantee that conventional generators will be ready to react to the power variations caused by the discontinuous resource availability. In the model, a $5 \%$ error is considered for RES generation (by including RES plants in the Generator Contingencies set), which has to be, therefore, covered by balancing reserve margins.

\section{Simulation and Results}

The model is simulated over one year, with an interval length of one hour. The software optimizes the dispatch of the defined generators, given the load and the constraints. Simulating the model allows its validation, by means of comparisons between the results and actual observations, and the identification of criticalities in the network.

The electricity production breakdown by sources, resulting from PLEXOS dispatch, fairly matches the one observed in reality and published by Italian TSO Terna [34]. Indeed, the contributions of each resource can be identified as follows: 16\% from coal, 33\% from natural gas, 39\% from RES and 12\% from imports. Among the renewable energy sources, the widest share is associated with hydro with $19 \%$, followed by PV with $7 \%$, wind and biomass with $5 \%$, and geothermal with $2 \%$. The number of equivalent hours attributable to each technology is summarized in Table 6.

Table 6. Equivalent hours of conventional power plants, resulting from the simulation.

\begin{tabular}{cc}
\hline Conventional Power Plants & Equivalent Hours \\
\hline CCGT & 2189 \\
Coal & 5052 \\
Oil/Gas & 1 \\
\hline
\end{tabular}


As witnessed in real operation, coal is used as baseload generation, while CCGT, although conceived as baseload as well, is mainly dispatched in peak periods. This is a consequence of the presence of large RES penetrations, which tend to reduce the operating hours of CCGT plants. As concerns peaking plants, such as oil- and gas-fed OCGTs, these are dispatched very rarely in reality. The model only uses them in a few instances in Sardinia.

This breakdown can be analyzed also on a daily basis, where some generation patterns can be noticed. Figures 4-9 show examples of generation profiles during winter and summer in the six Italian zones studied by the model.

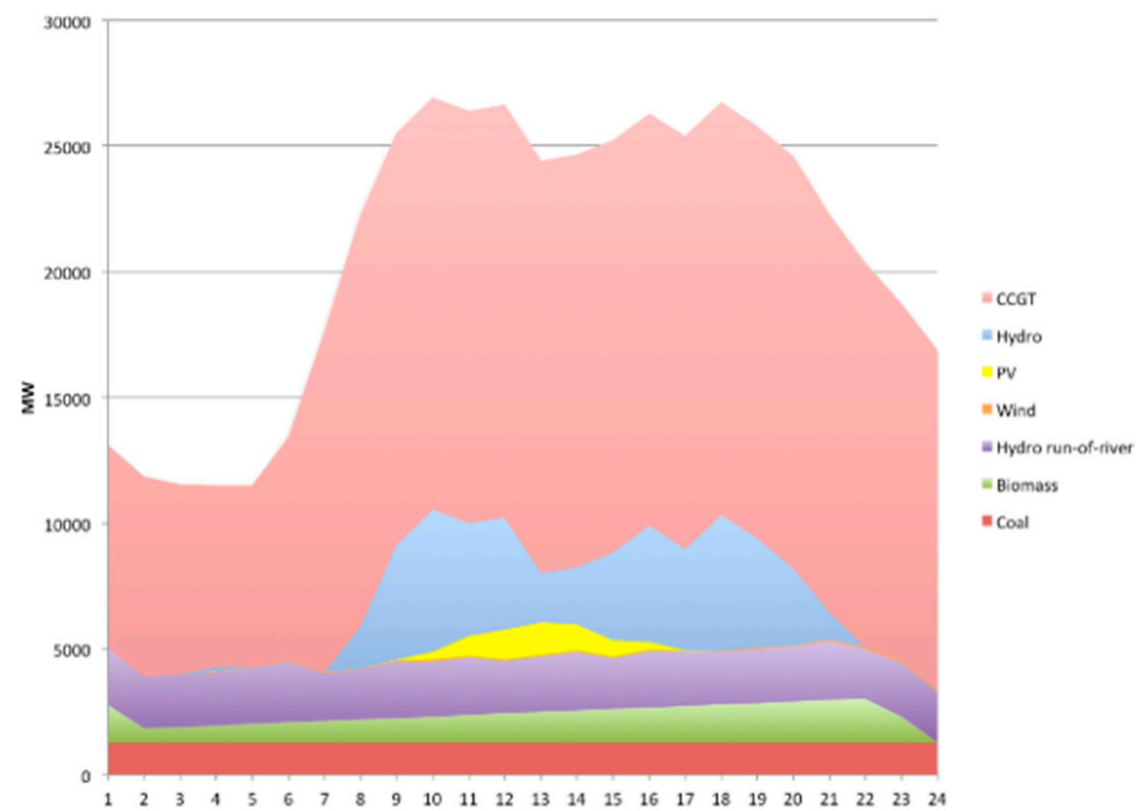

(a)

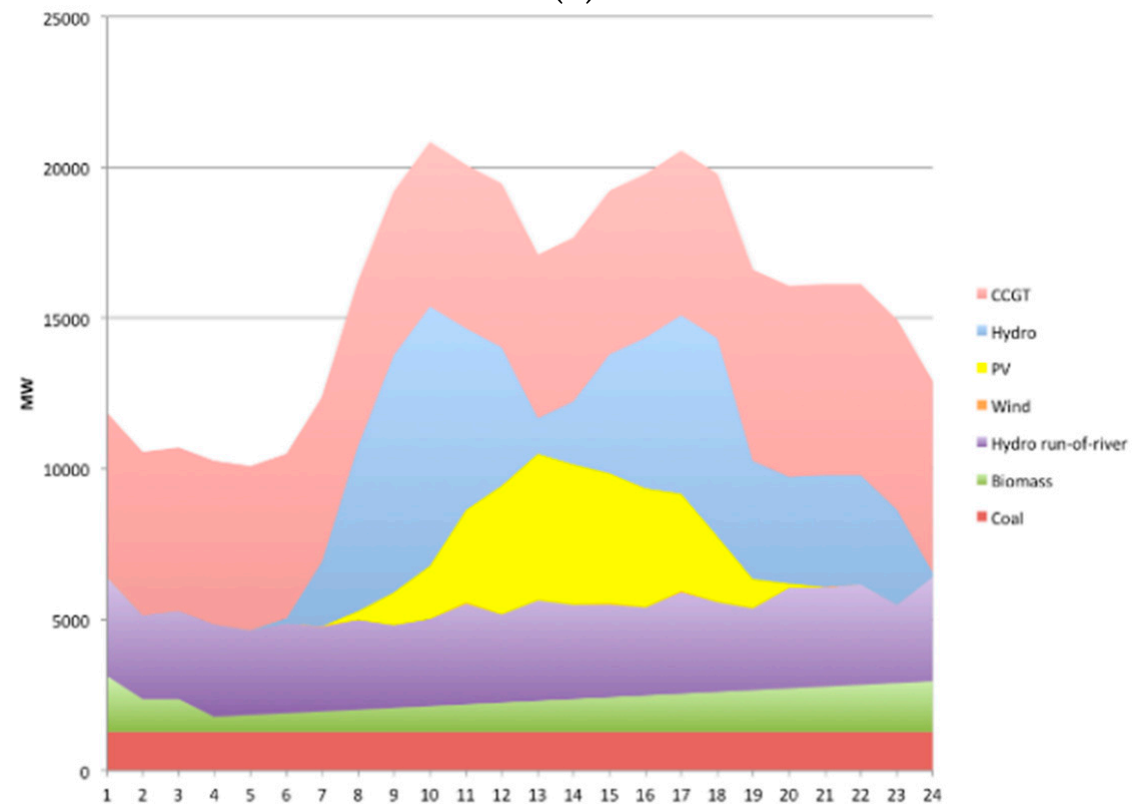

(b)

Figure 4. Generation profile NORD (a) NORD winter (b) summer. 


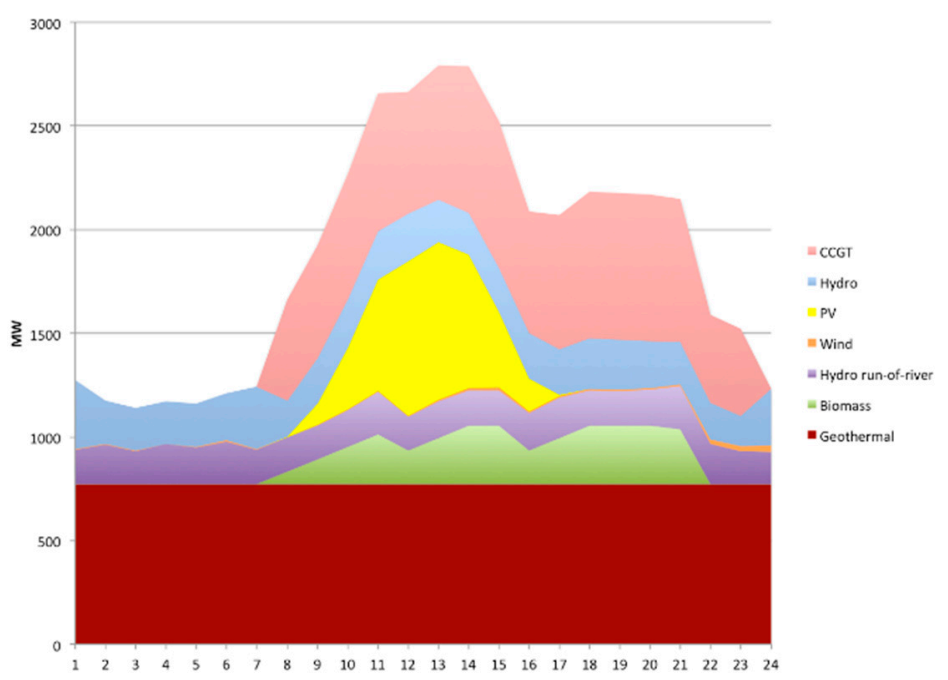

(a)

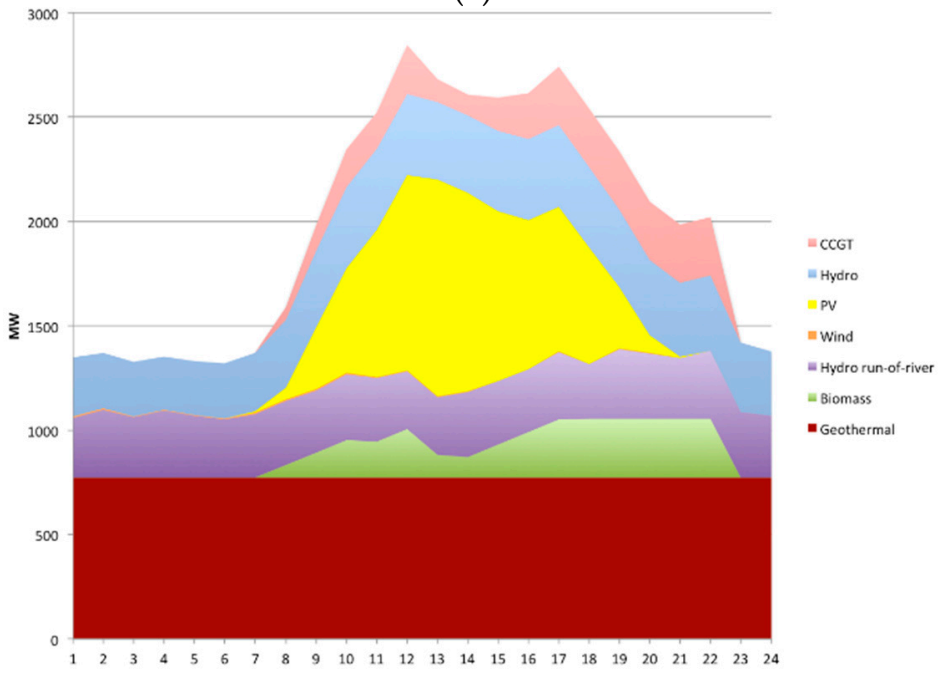

(b)

Figure 5. Generation profile-CNORD (a) winter and (b) summer.

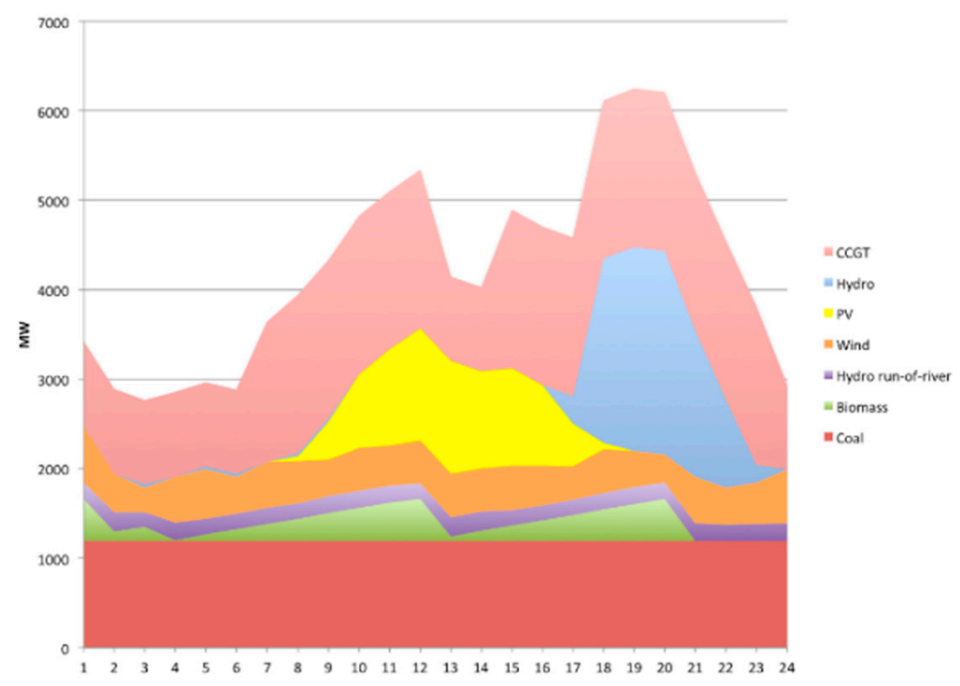

(a)

Figure 6. Cont. 


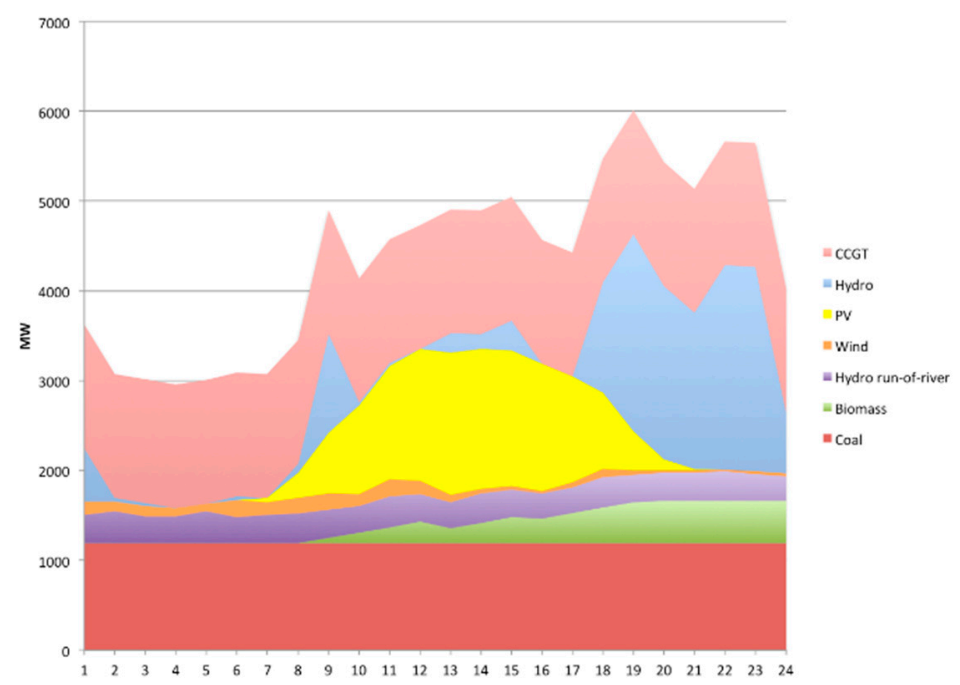

(b)

Figure 6. Generation profile-CSUD (a) winter and (b) summer.

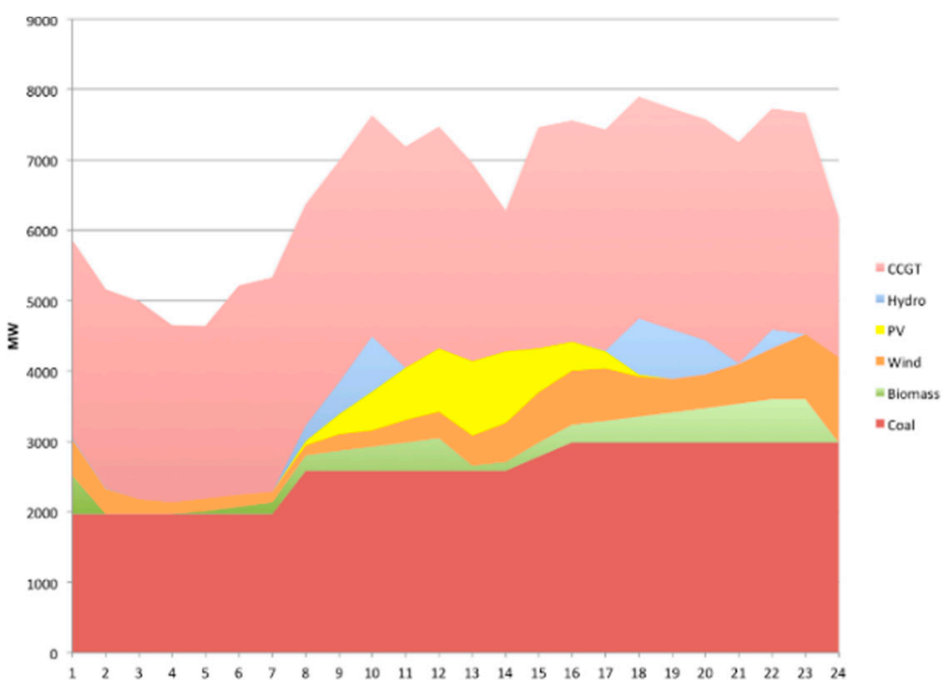

(a)

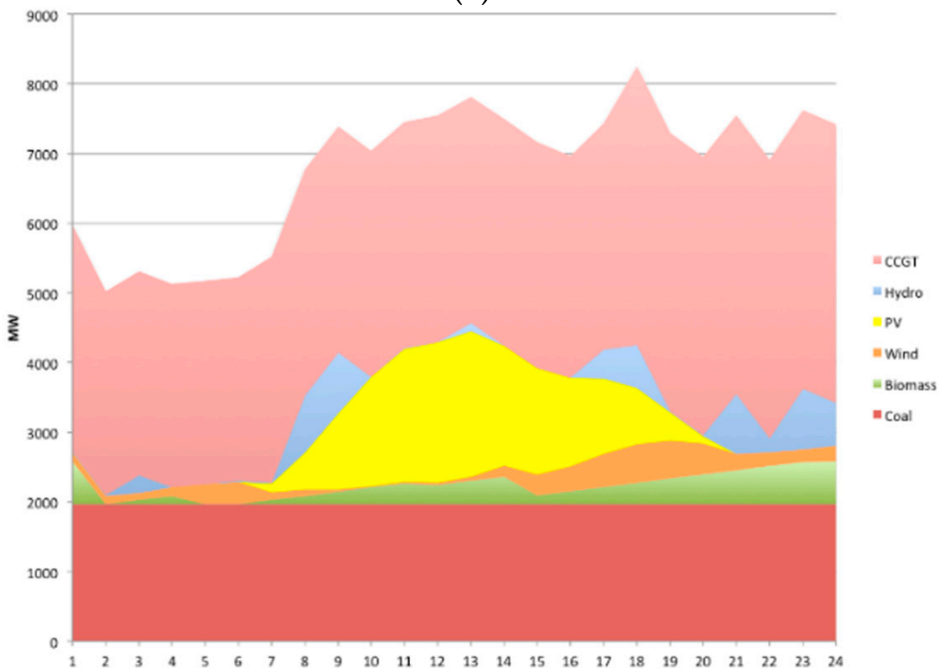

(b)

Figure 7. Generation profile-SUD (a) winter and (b) summer. 


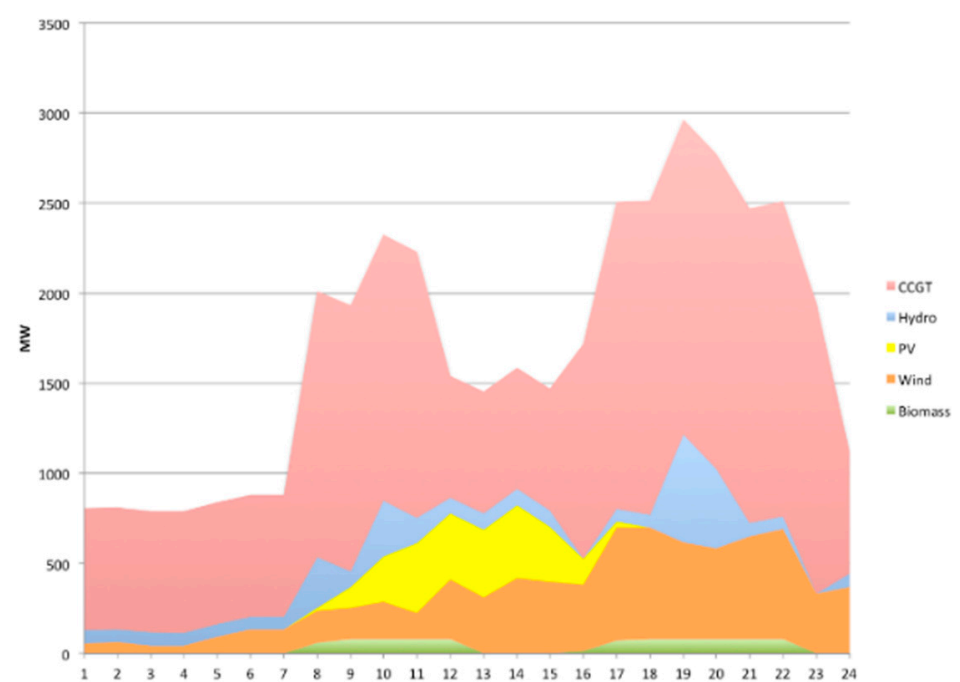

(a)

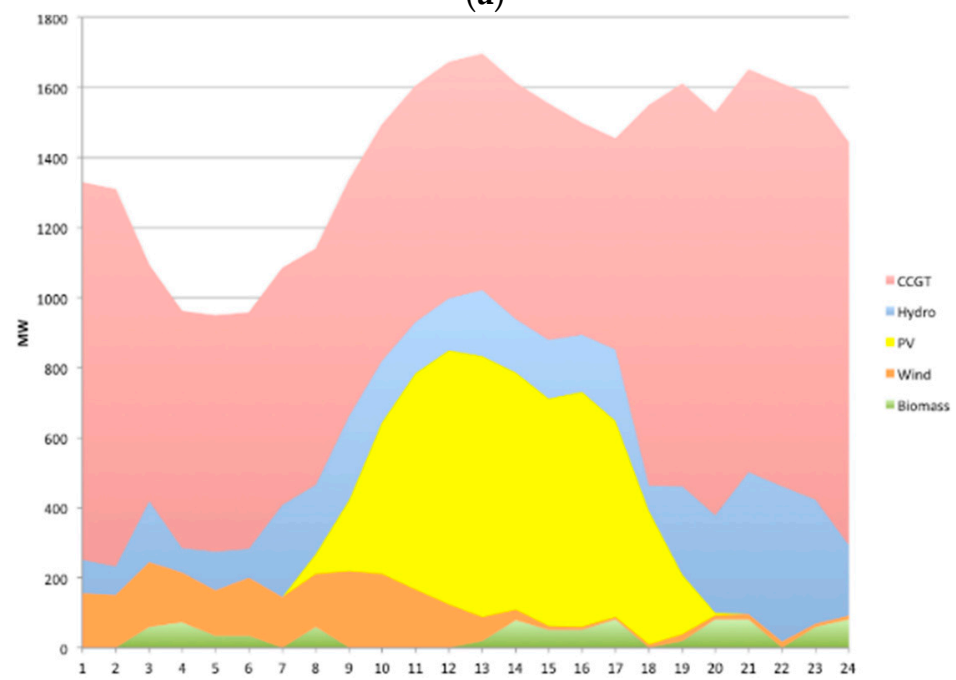

(b)

Figure 8. Generation profile-SICI (a) winter and (b) summer.

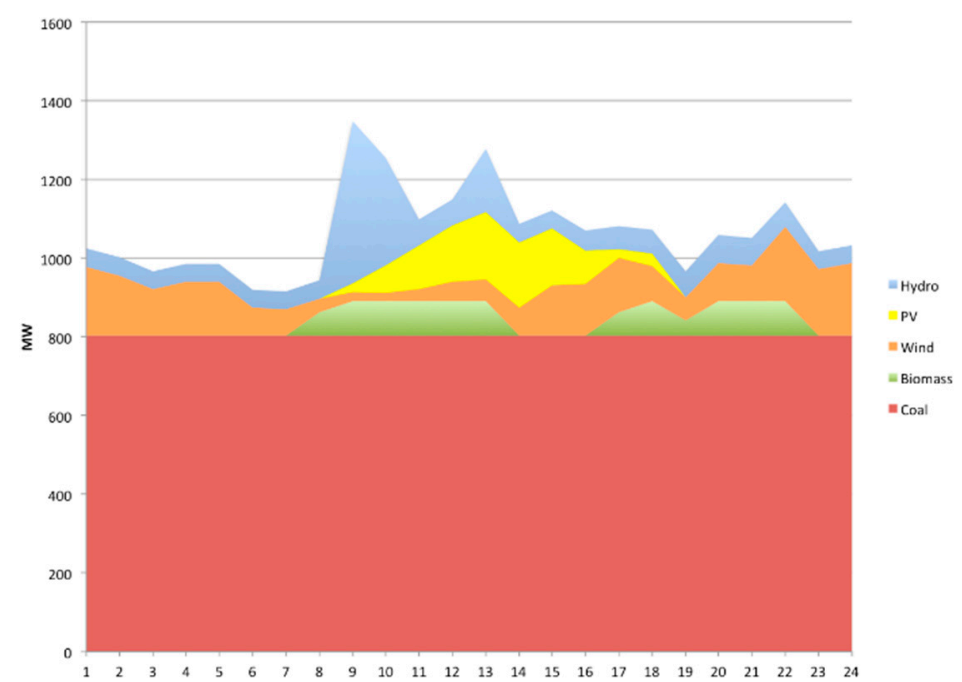

(a)

Figure 9. Cont. 


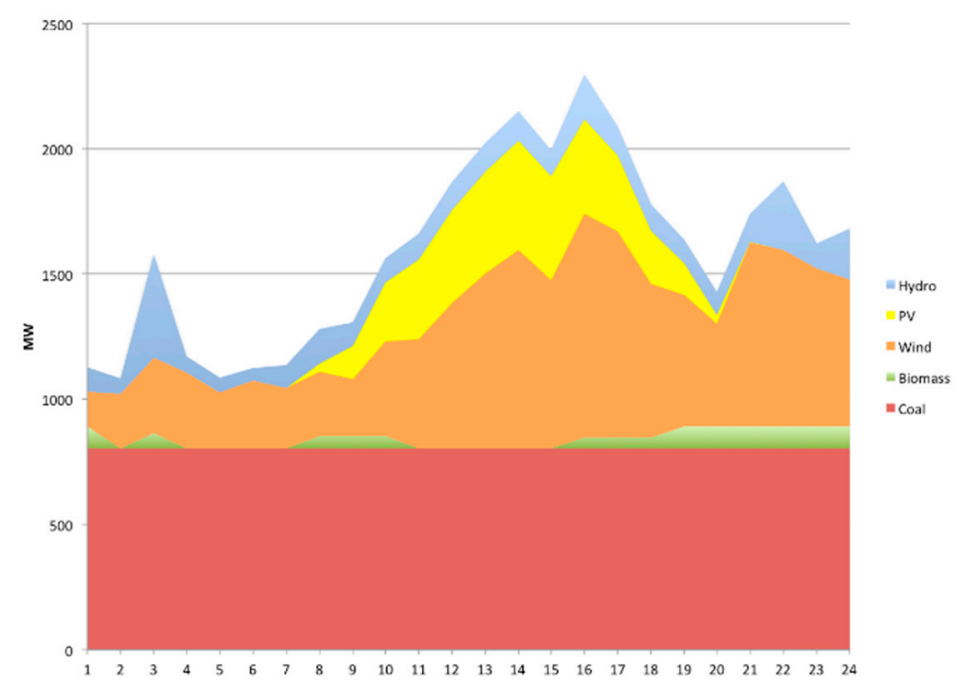

(b)

Figure 9. Generation profile-SARD (a) winter and (b) summer.

It is necessary to note that the dispatch of conventional generating units has to take into account the constraints on their minimum stable load and on reserve margins. For such reason, the maximum generating power of a unit is at least below the mandatory upward primary reserve margin (and even lower if the plant contributes to other types of reserves), while the minimum generating power is always above the minimum stable level increased by (at least) the downward primary reserve band.

Figure 7 shows an example of correlation between the load curve and the price profile throughout one day (in particular, it refers to node SUD in January). The presence of high PV penetration might distort this correlation, since a high amount of "free" generation during peak hours (around midday) tends to bring down the price of electricity on the market. Figure 10 compares actual and simulated data on a monthly basis.

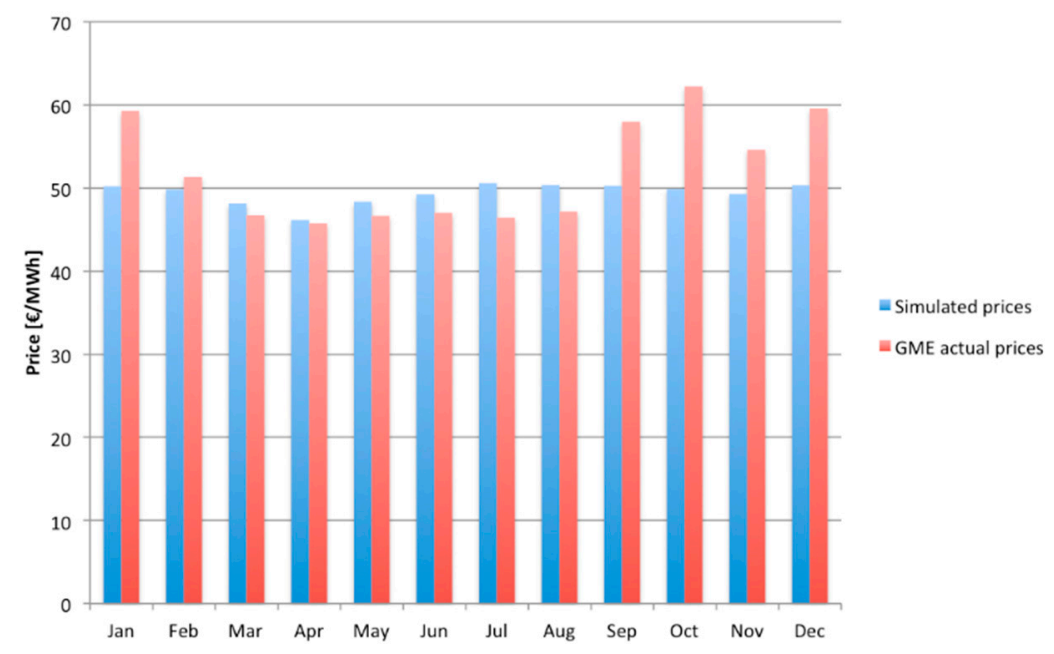

Figure 10. Average monthly prices: comparison between simulated and actual values.

\section{Criticalities}

The main critical issues highlighted by the model are wind curtailment and line congestions. The two are, in fact, correlated, since solving congestions also helps wind over-generation in one node be distributed in the neighboring zones. 
The total amount of wind generation curtailed over the simulation year adds up to $119.8 \mathrm{GWh}$. This represents the $0.92 \%$ of annual electricity generation from wind resources. Wind curtailment amounted to 248 GWh in 2013 , corresponding to $1.8 \%$ of that year's generation. Figure 10 includes both curtailments due to stability issues and those made necessary by local transmission constraints. Only the former are included in the simulation accounting for $51 \%$ of wind curtailment in 2013. It can be observed, indeed, that the value of total wind curtailment resulting from the simulation is consistent with the expected one, with variations attributable to different wind availability and load patterns in 2014. Figure 11 shows the occurrence of wind curtailment on a monthly basis throughout the year.

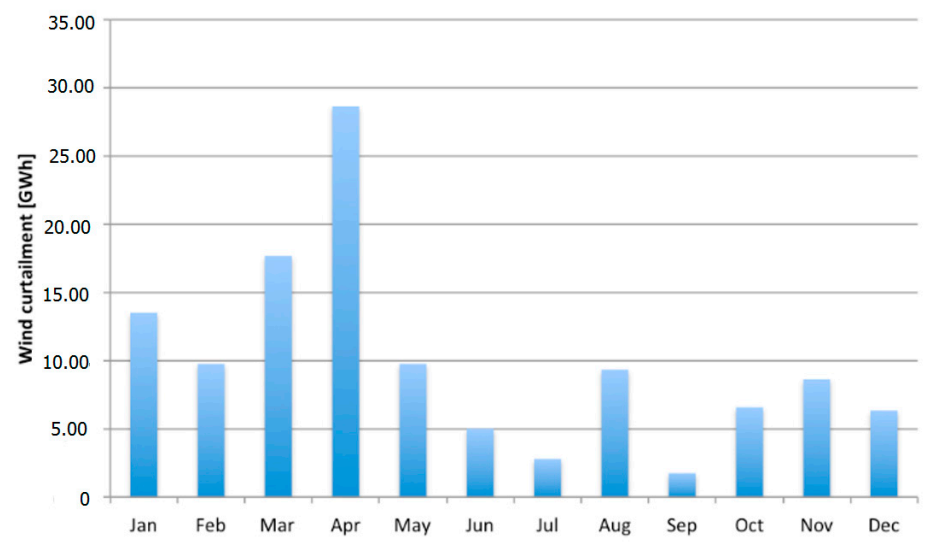

Figure 11. Monthly values of wind curtailment, resulting from the simulation.

Most wind curtailment occurs in the SUD zone, where the majority of wind capacity is concentrated. Here, wind curtailment amounts to $78 \mathrm{GWh}$ in one year. The islands (Sicily and Sardinia) are also characterized by significant curtailment events, due to their large RES penetrations, the limited exchange possibilities, and the higher need for reserves and synchronous generation. Wind curtailment data for Sicily and Sardinia, resulting from the simulation, total 23 and 19 GWh, respectively. Figure 12 shows the monthly distribution of wind curtailment in the three zones: SUD, SICI, and SARD.

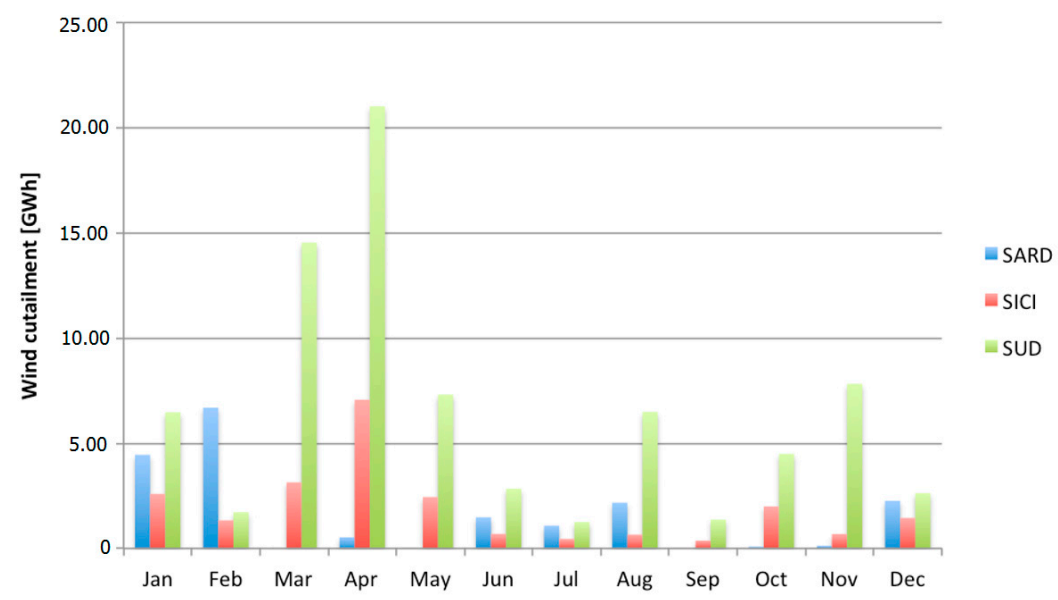

Figure 12. Monthly wind curtailment values in the zones SUD, SICI, and SARD, resulting from the simulation.

It can be observed that both Southern Italy and Sicily present a peak in spring, with particularly high values in April; conversely, the highest levels of curtailment in Sardinia are registered in January and February. The results relevant to the six zones are summarized in Table 7. 
Table 7. Wind curtailment values in each zone, resulting from the simulation.

\begin{tabular}{lc}
\hline Zone & Wind Curtailment (GWh/Year) \\
\hline SUD & 77.97 \\
SICI & 22.91 \\
SARD & 18.90 \\
CSUD & 0.00 \\
CNORD & 0.03 \\
NORD & 0.00 \\
\hline
\end{tabular}

Moreover, it is significant to notice that wind curtailment, as expected, occurs mainly during weekends, when the load is low and, therefore, over-generation risk is higher. Table 8 shows the days characterized, according to the model, by the highest values of wind curtailment. In fact, five out of 10 days are Sundays, two are Saturdays, one is a festivity (25 April) and only two days are outside the weekend.

Table 8. Days with highest wind curtailment.

\begin{tabular}{ccc}
\hline Days & Day & Wind Curtailment (MWh/Day) \\
\hline 13 March & Thursday & 2734 \\
23 March & Sunday & 4357 \\
6 April & Sunday & 3469 \\
15 April & Tuesday & 2778 \\
25 April & Friday & 2995 \\
31 May & Saturday & 4022 \\
24 August & Sunday & 3610 \\
12 October & Sunday & 2873 \\
1 November & Saturday & 3130 \\
2 November & Sunday & 3245 \\
\hline
\end{tabular}

Consistently with the values of wind curtailment, which suggest the presence of critical conditions mainly in the SUD zone, congestions are concentrated in this area as well. Indeed, the constraints present in the transmission network linking SUD to the neighboring nodes force the TSO to curtail the excess wind generation, that cannot be evacuated to areas with higher loads.

The interconnectors linking Italy to the neighboring countries also present high incidence of congestions. In particular, the connections with France and Austria are the most affected ones. This suggests that expanding the network towards such countries might enhance exchanges, thus helping guarantee the stability of the system and probably reduce the electricity price.

\section{Wind Integration and HVDC in Italy}

Southern Italy is characterized by large volumes of wind and solar generation. When strong winds occur during low load periods and the extra-production cannot be evacuated through the existing lines to other zones, then it needs to curtail wind generation. It follows that the possibility to transport the generation surplus where the load is high enough to accept it is likely to reduce the occurrence of wind curtailment.

In Italy, the SUD node presents relatively low loads. A possibility envisaged by this study is that of building a line able to connect SUD and NORD zones. The latter is, indeed, particularly suitable to accommodate the over-generation from RES resources, thanks to the following characteristics: 
- It encompasses some of the most important load centers of the country and presents the highest levels of electricity consumption;

- It is interconnected to the neighboring countries, so that the extra-generation can be possibly exported to maintain the stability of the control area;

- It is characterized by the presence of large hydro facilities, which can behave as storage plants by pumping water back to the reservoir when RES overproduce (compatible with economical logics and environmental or other types of constraints).

The related connection should be able to transport rather high amounts of power for a long distance (about $800 \mathrm{~km}$ ). In order to limit the losses, which over such a distance would be too high in AC, a HVDC line is here considered as the best alternative. A HVDC link also has the advantage of being an asynchronous system. This allows it to be interconnected with systems having different frequency or phase. This is the case for Northern African countries, which might represent an interesting power exchange node in the future. In particular, the association of Mediterranean TSOs (Med-TSO) is working towards market integration and a common development of the Mediterranean countries' power systems, by means of new interconnections that might see Italy as a strategic interface. The distance to be covered by the proposed HVDC corridor amounts to roughly $800 \mathrm{~km}$. Figure 13 shows the hypothetical path covered by the proposed HVDC line.

A suitable capacity for the line is selected based on the need to reduce wind curtailment. Given the line length and its maximum power capacity, the voltage level and the suitable line and converter configuration is chosen, based on the indications by CIGRÉ (International Council on Large Electric Systems) [37]. The alternatives considered in the study, in terms of rated power and voltage level, are the following:

$11000 \mathrm{MW} / \pm 300 \mathrm{kV}$

$21500 \mathrm{MW} / \pm 300 \mathrm{kV}$

In both cases, the connection is made of a single bipole, which is the most suitable for the involved power ratings. A symmetrical monopolar configuration would also be possible in order to increase the reliability of the system. However, the bipolar arrangement is preferred for economical reasons.

As concerns the converter configuration, stations with less than $3000 \mathrm{MW}$ rating (as in this case) use only one converter per pole. With low power ratings, as the ones considered here, both Line-Commutated Converter (LCC) and Voltage Source Converter (VSC) converters are possible. Line Commutated Converters are a less expensive and more mature technology. However, their operation is subject to severe issues in case of disturbances. Indeed, since they exploit the AC voltage transit across the zero value to start the conduction through the thyristors, any voltage disturbance, such as harmonics, leads to commutation failures and, eventually, to converters malfunctioning. Conversely, VSC converters do not need an active network, so that they can compensate the above-mentioned problems, they can supply passive loads and they do not require filters or any reactive power compensation. For such reasons, they are more suitable in networks characterized by a large penetration of renewables, where less synchronous machines are connected to the grid and the system inertia is lower. VSC converters are, therefore, considered to be more appropriate for this project proposal. Their higher cost is typically compensated by the absence of other pieces of equipment, such as filters, that are not required for the operation of VSC. 


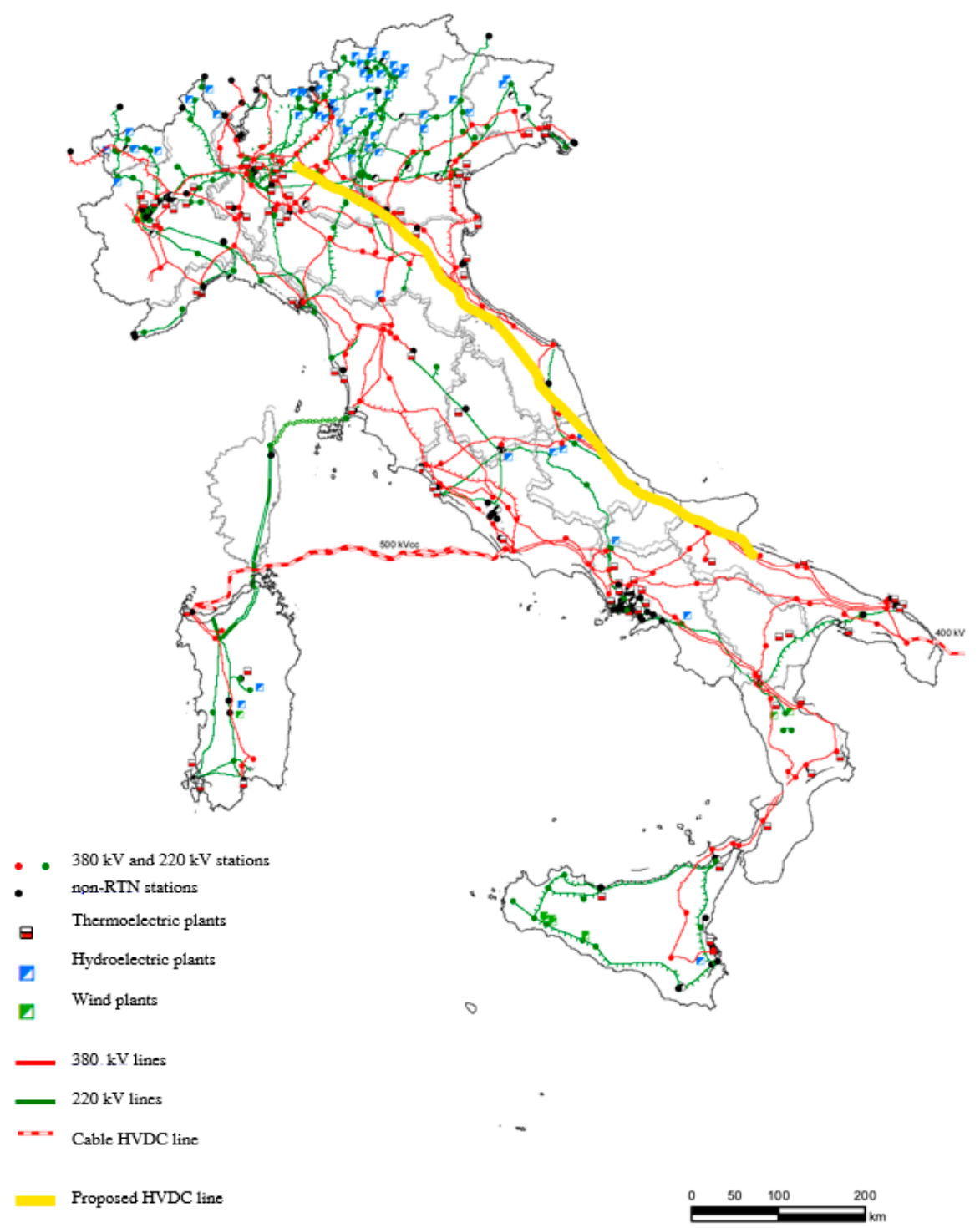

Figure 13. Hypothetical path of the proposed HVDC line.

\section{Simulation Results}

The two scenarios, each including one of the HVDC alternatives proposed, are simulated on PLEXOS. The simulation allows analysis of the effects that the corridor has on the power system and, specifically, on the wind curtailment issue.

\subsection{Wind Curtailment}

The main effect of the introduction of a SUD-NORD HVDC connection is the drop of wind curtailment. The greatest reduction is registered in the SUD zone, with a significant decrease also in Sicily. The curtailment occurring in Sardinia, instead, is generally unchanged, since the exchange flows between the island and the continent are not modified by the introduction of the HVDC line.

A major reduction of wind curtailment results from both the alternatives analyzed. In Case 1 (HVDC capacity of $1000 \mathrm{MW}$ ), the overall annual curtailment amounts to $31.9 \mathrm{GWh}$, or $0.25 \%$ of the total yearly wind energy production. This represents a $73 \%$ contraction with respect to the $119.8 \mathrm{GWh}$ resulting from the base case. The higher connection capacity in Case 2 helps decrease further the levels of wind curtailment, leading to a total figure of $25.0 \mathrm{GWh}$ per year, i.e., $0.19 \%$ of the electricity annually 
produced by wind resources. A 79\% reduction is, therefore, registered with respect to the current situation. Figure 14 compares the wind curtailment in the three cases analyzed.

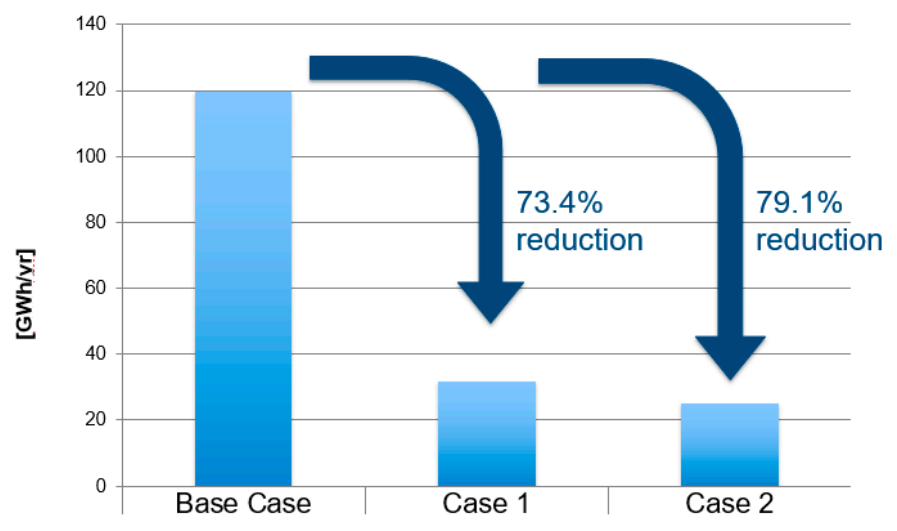

Figure 14. Comparison of wind curtailment in different cases.

Figure 15 compares the monthly values of wind curtailment in the three cases analyzed (Base Case, Case 1, and Case 2).

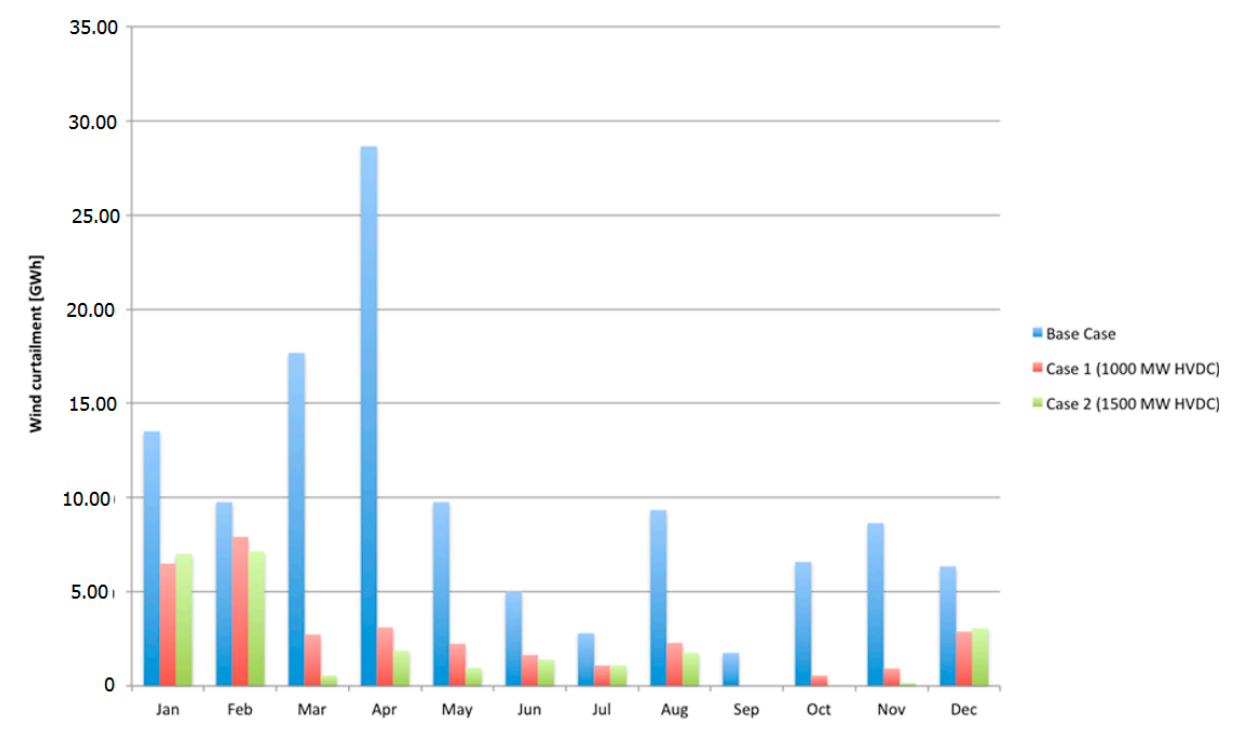

Figure 15. Comparison of wind curtailment levels resulting from the HVDC connection implementation.

Table 9 summarizes the results discussed above and shows the values of wind curtailment registered in each zone for the three cases. It can be observed that in some months Case 2 seems to lead to worse results in terms of wind curtailment than Case 1. The dispatch of energy is, indeed, performed differently in the two cases, so an increase of wind curtailment in a few hours may occur. However, wind curtailment is globally reduced by the implementation of a line with higher power rating, such as the one proposed in Case 2. As already mentioned, most of wind curtailment reduction occurs in the SUD node, which is characterized by the highest levels in the Base Case. It can be observed that SUD and SICI are affected significantly by the implementation of the HVDC connection. Indeed, their over-generation is now much more easily shifted to the NORD zone, where the load is high enough to accommodate it. The effect on wind curtailment in Sardinia, instead, is very modest, thus making the island the most problematic area as concerns curtailment, when the HVDC connection is implemented. This suggests that a direct connection SUD-NORD leaves unaffected those regions, like Sardinia, that 
are not immediate neighbors of the SUD zone. Indeed, the over-generation from Sardinia, transported to CSUD, cannot take advantage of the new connection to find suitable exploitation.

Table 9. Wind curtailment values in the three cases considered.

\begin{tabular}{cccc}
\hline Zone & Base Case & Case 1 & Case 2 \\
\hline Annual Wind Curtailment (GWh) & 119.8 & 31.9 & 25.0 \\
Percentage of total & $0.92 \%$ & $0.25 \%$ & $0.19 \%$ \\
Wind curtailment reduction (GWh) & - & 87.9 & 94.8 \\
Percentage reduction & - & $73.4 \%$ & $79.1 \%$ \\
CNORD & 0.03 & 0.00 & 0.02 \\
CSUD & 0.00 & 0.00 & 0.13 \\
NORD & 0.00 & 0.00 & 0.00 \\
SARD & 18.90 & 17.89 & 17.99 \\
SICI & 22.91 & 5.47 & 3.78 \\
SUD & 77.97 & 8.50 & 3.08 \\
\hline
\end{tabular}

\subsection{Congestions}

The new HVDC connection also helps relieve congestions on the lines departing from the SUD zone which are the ones most subject to congestion. Figure 16 shows the variations in the hours congested for the lines SICI-SUD and SUD-CSUD respectively.

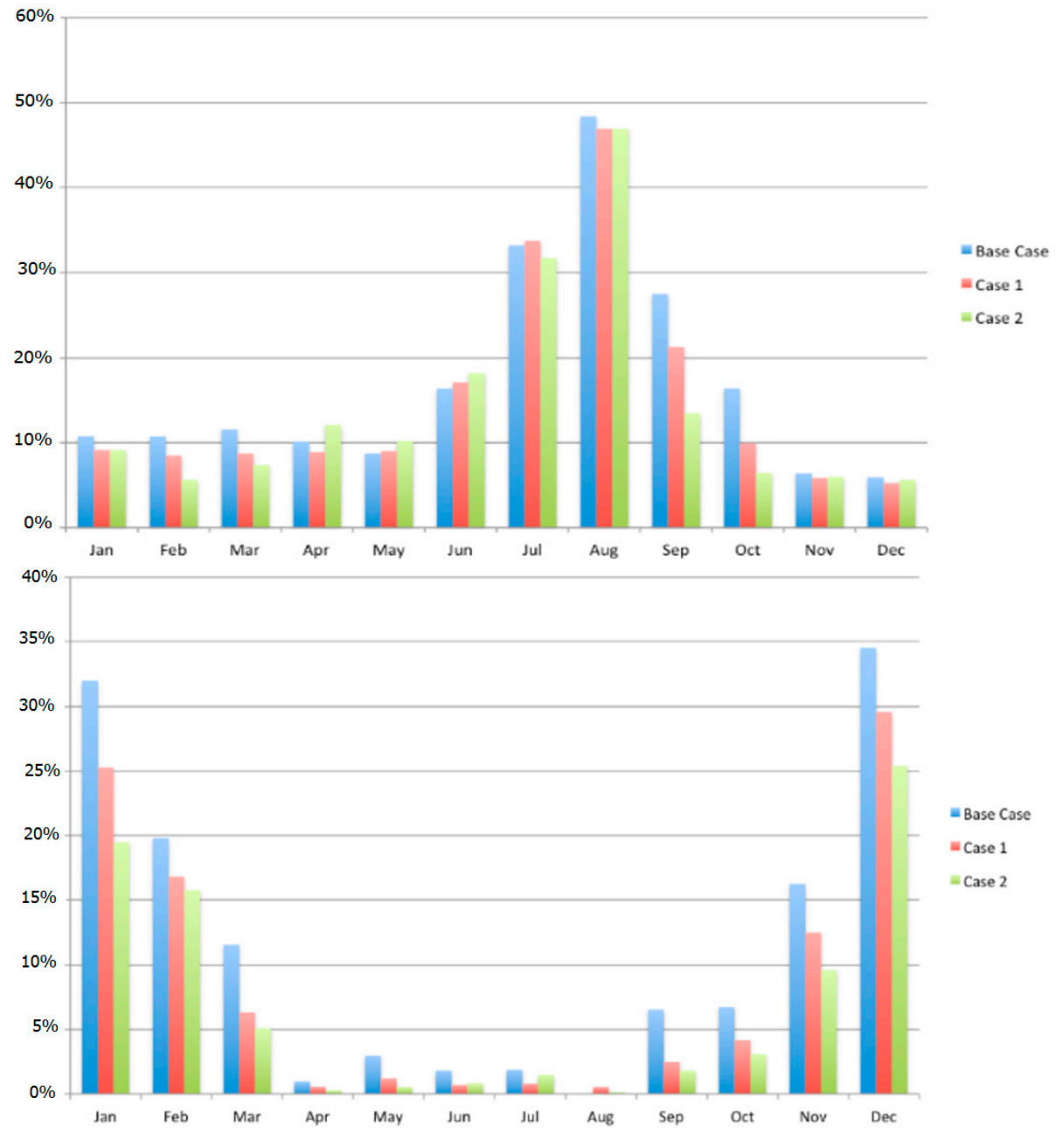

Figure 16. Percentage of hours in each month in which the SICI-SUD line is congested, in the three cases analyzed. 
Table 10 summarizes the total amount of hours within one year in which the mentioned lines result in congestion and shows how the construction of the HVDC line reduces these figures.

Table 10. Hours in which SICI-SUD and SUD-CSUD lines are congested during one year in the three cases analyzed.

\begin{tabular}{ccc}
\hline Scenario & SICI-SUD & SUD-CSUD \\
\hline Base Case & 1511 & 984 \\
Case 1 & 1352 & 735 \\
reduction & 159 & 249 \\
Case 2 & 1270 & 607 \\
reduction & 241 & 377 \\
\hline
\end{tabular}

As concerns the proposed HVDC line, it also experiences major congestion problems. Indeed, its capacity is fully exploited in both its directions for many hours per year. The total amount of hours in which the HVDC line results in congestion over the simulated year is for Case 1 equal to $6607 \mathrm{~h}$ and Case 2 equal to $5643 \mathrm{~h}$. As expected, the larger power rating involved in Case 2 reduces the congestion phenomenon along the line. It can be observed that they are rather high, hinting that the transmission would benefit from a larger rating of the line. Indeed, the flow is heavily limited by the connection capacity chosen and an increase of the latter would certainly lead to greater exchange flows between the two nodes. However, since huge reductions in wind curtailment are already realized with the ratings considered in Case 1 and 2, the marginal improvement achievable with an increase of line capacity is expected to be very low; on the other hand, an expansion of power capacity would lead to higher capital costs, whose increase is not justified by the limited benefits in wind curtailment reduction.

\section{Economics of the HVDC System}

A simplified economic analysis can be performed in order to evaluate the possible economic benefits brought by the construction of the HVDC connection and the consequent reduction of wind curtailment. The costs of an HVDC system are dominated by two major elements: the investments relative to DC lines and converter stations. The methods for cost calculations here used refer to the indications outlined by CIGRÉ [37].

The cost of conductors is, in general, lower in DC than in AC, since, for the same power rating, the former needs two phases while the latter needs three. The cost of the necessary lines can be evaluated as a function of transmission voltage and of the pole conductor configuration. The latter is defined by the number of conductors used and the relevant size. The following equation has been proven to fully describe the dependence of the lines' cost on the above-mentioned parameters in Equation (2):

$$
C_{\text {line }}=a+b V+S(c N+d)
$$

where $C_{\text {line }}$ is the cost of the line in US\$ $/ \mathrm{km} ; V$ is the pole-to-ground voltage in $\mathrm{kV} ; N$ is the number of conductors per pole; $S$ is the total aluminum cross section in MCM; $a, b, c$, and $d$ are parameters resulting from curve regression.

In the study here considered, the parameters of the regression are set to the following values: $a=69,950 ; b=115.37 ; c=1.177$, and $d=10.25$. At $300 \mathrm{kV}$, a possible configuration for Case 1 (1000 MW power capacity) is using two Kiwi conductors, i.e., ACSR conductors having an aluminum area of $2167 \mathrm{MCM}\left(1 \mathrm{MCM}=0.5067 \mathrm{~mm}^{2}\right)$. In Case 2 (1500 MW rating), the most suitable configuration is determined to be three conductors with $2515 \mathrm{MCM}$ aluminum area. These inputs lead to the overall DC line costs shown in Table 11. The lines considered have a length of $800 \mathrm{~km}$. 
Table 11. DC lines estimated costs in the two cases analyzed.

\begin{tabular}{ccc}
\hline Scenario & Marginal Cost $(\mathbf{k} € / \mathbf{k m})$ & Total Cost $(\mathbf{M € )}$ \\
\hline Case 1 & 141.78 & 113.4 \\
Case 2 & 185.72 & 148.6 \\
\hline
\end{tabular}

Converter stations are generally the main cost contribution to the overall investment. Their cost can be estimated approximately as a function of their power rating and DC voltage level. The following equation is commonly valid in Equation (3):

$$
C_{c S}=A\left(V^{B}\right)\left(P^{C}\right)
$$

where $C_{C S}$ is the cost of the converter station in millions of US\$; $V$ is the pole voltage in $\mathrm{kV} ; P$ is the bipole power in MW; $A, B$, and $C$ are equation parameters. For ratings below $4000 \mathrm{MW}$, the recommended values for the parameters are the following: $A=0.698 ; B=0.317$, and $C=0.557$. The resulting converters' costs in the two alternatives proposed are summarized in Table 12.

Table 12. Converter stations estimated costs in the two cases analyzed.

\begin{tabular}{lc}
\hline Scanario & Cost $(\mathbf{M € )}$ \\
\hline Case $\mathbf{1}$ & 177.7 \\
Case 2 & 222.8 \\
\hline
\end{tabular}

A summary of the total investment costs associated to HVDC project in the two configurations considered is shown in Table 13.

Table 13. Total capital costs associated to the HVDC systems proposed.

\begin{tabular}{lc}
\hline Scenario & Total Capital Cost $(\mathbf{M} €)$ \\
\hline Case 1 & 291.1 \\
Case 2 & 371.4 \\
\hline
\end{tabular}

\section{Wind Curtailment Reduction Benefits}

The compensation for MPE includes the day-ahead market price at which the electricity produced by wind plants was sold. Therefore, when wind generation is curtailed, plant owners receive just the payment for the curtailed electricity itself and not the lost incentives. However, the period of time for which the incentives are granted to the plant is extended, in order to allow for the recovery of the incentives as well (Feed-in Tariffs (FiT), in the case of wind in Italy). The evaluation of the overall expense, thereby, has to compensate both the energy value and the incentives, although the latter component is deferred in time.

Since most of the installed wind capacity is represented by big plants (with rated power above $5000 \mathrm{~kW}$ ) [38,39], the corresponding FiT value can be used for the following approximate calculations. The relevant FiT is, therefore, $127 € / \mathrm{MWh}$. As some plants whose energy is curtailed are actually smaller than $5 \mathrm{MW}$, the estimation here performed is likely to underestimate the actual benefits from wind curtailment reduction. Given the difference in wind curtailment produced by the two HVDC alternatives considered, the following economic benefits are achieved for Case 1 equal to 11.2 $\mathrm{M} €$ /year and Case 2 equal to $12 \mathrm{M€} /$ year. These values neglect the fact that each year some plants hit the deadline of their incentive period, so that the compensation for wind curtailment only includes the market price for electricity. However, also new plants are built year by year which access the incentive program. With these hypotheses and simplifications, the payback time for the investment in the HVDC system is of 26 years and 31 years for Case 1 and Case 2, while the Internal Rate of Return is 3\% and 
$2 \%$ respectively. It can be observed that a preliminary economic analysis does not seem to favor the HVDC solution, which, although long-lasting, appears to be rather expensive. Indeed, the feasibility of HVDC systems to increase the reliability of the power system is demonstrated by other similar works [40]. However, the benefits brought by the HVDC system are not merely economic. Indeed, other aspects should be considered that back this solution, such as increased transmission reliability and environmental advantages. The latter come from the fact that, by reducing wind curtailment, the HVDC system proposed would be able to integrate more wind capacity. This makes higher RES penetrations feasible, thus enhancing the development of renewable resources in Italy.

\section{Conclusions}

This work analyzed the issue of wind curtailment, its causes, and the experience of the countries that have been mostly affected so far. Wind curtailment is determined by either local transmission constraints or grid stability concerns. The former are due to the delayed development of transmission infrastructures with respect to wind farms, and can be solved by suitably expanding the local connections. Grid stability, on the other hand, is threatened by the presence of variable non-programmable energy sources, such as wind and PV. They, indeed, make it harder to maintain the system balance, while satisfying the requirements on ancillary services provision and the constraints imposed by conventional power plants. A solution to such a problem may come from various alternatives, some of which have already been investigated by the different national TSOs.

An option has been here studied in detail for the Italian case. This consists of creating a HVDC connection between Southern Italy (where most of the renewable production is concentrated) and Northern Italy (where the biggest load centers are located). The line should cover roughly $800 \mathrm{~km}$ and would shift large amounts of wind generation where it can be consumed, avoiding it being curtailed when the load in the South is low. Direct Current is chosen because the long distance involved makes it more economical and more efficient compared to an AC connection. Moreover, a DC link is more controllable and it avoids the propagation of disturbances. Finally, it can connect systems that are (even temporarily) at different frequencies or phases. All these characteristics enable it to be used securely and effectively in a network with large penetrations of variable RES, which decrease the inertia of the system and tend to increase grid disturbances. Similar solutions have been proposed in other works to mitigate problems of renewable sources curtailment [41].

A model of the Italian system was created on the PLEXOS Integrated Energy Model by Energy Exemplar, a software that, given the data on generation, load and other system constraints, is able to simulate the economic dispatch as performed in practice, by the electricity market. This gives the possibility to make predictions on the effects of system modifications. After validating the model by observing that, specifically as concerns wind curtailment figures, the results found match the expected values from reality, the creation of the above-mentioned HVDC line was implemented. In particular, two cases were considered, in order to understand the effect of two different power ratings chosen for the line: Case 1, featuring a $1000 \mathrm{MW} /$ $\pm 300 \mathrm{kV}$ connection, and Case 2, featuring a $1500 \mathrm{MW} / \pm 300 \mathrm{kV}$ one. In both the alternatives, VSC converters were considered as most suitable, mainly for their better performance under disturbances, which makes them more appropriate when dealing with a RES-dominated network.

The application of such a connection, according to the simulation performed, leads to wind curtailment reductions of the order of $73.4 \%$ and $79.1 \%$, respectively in Case 1 and 2, with respect to the current levels. This would lead to very marginal values of wind curtailment overall in Italy. The reduction is mainly registered in Southern Italy and partially in Sicily. Despite the long payback times involved in such a project (estimated around 26 and 31 years, respectively), the great wind curtailment reductions determined make the implementation of an HVDC connection very interesting. Indeed, this would imply first of all the capability to more easily and efficiently integrate renewable energy sources, which are bound to increase further in the coming years. Moreover, it would allow 
a better control of power flows on the network and a more secure operation thanks to limited disturbances propagation.

Author Contributions: Morris Brenna and Federica Foiadelli proposed the core idea, developed the models. Michela Longo performed the simulations, exported the results and analyzed the data. Dario Zaninelli revised the paper. Morris Brenna, Federica Foiadelli and Michela Longo contributed to the design of the models and the writing of this manuscript.

Conflicts of Interest: Declare conflicts of interest or state.

\section{Abbreviations}

The following abbreviations are used in this manuscript:

$\begin{array}{ll}\text { ACSR } & \text { Aluminium-Conductor Steel-Reinforced } \\ \text { BAU } & \text { Business as Usual } \\ \text { CCGT } & \text { Combined Cycle Gas Turbine } \\ \text { CF } & \text { Capacity Factor } \\ \text { DSM } & \text { Demand Side Management } \\ \text { ENTSO-E } & \text { European Network of Transmission System Operators for Electricity } \\ \text { EU } & \text { European Union } \\ \text { FCR } & \text { Fixed Charge Rate } \\ \text { FiT } & \text { Feed-in Tariff } \\ \text { GHG } & \text { Greenhouse Gas } \\ \text { HVAC } & \text { High-Voltage Alternate Current } \\ \text { HVDC } & \text { High-Voltage Direct Current } \\ \text { LCC } & \text { Line Commutated Converter } \\ \text { MCG } & \text { Minimum Conventional Generation } \\ \text { MCM } & \text { Thousands of circular mils } \\ \text { MPE } & \text { Wind curtailment } \\ \text { O\&M } & \text { Operation \& Maintenance } \\ \text { OCGT } & \text { Open Cycle Gas Turbine } \\ \text { PAN } & \text { Italian National Energy Plan } \\ \text { PV } & \text { Photovoltaics } \\ \text { RES } & \text { Renewable Energy Source } \\ \text { RES-E } & \text { Renewable Energy Source for Electricity } \\ \text { RES-H } & \text { Renewable Energy Source for Heating } \\ \text { RES-T } & \text { Renewable Energy Source for Transportation } \\ \text { SEN } & \text { Italian National Energy Strategy } \\ \text { TSO } & \text { Transmission System Operator } \\ \text { VSC } & \text { Voltage Source Converter }\end{array}$

\section{References}

1. Ferrara, R. The Smart City and the Green Economy in Europe: A Critical Approach. Energies 2015, 8, 4724-4734. [CrossRef]

2. Ackermann, T.; Carlini, E.M.; Ernst, B.; Groome, F.; Orths, A.; O'Sullivan, J.; de la Torre Rodriguez, M.; Silva, V. Integrating Variable Renewables in Europe: Current Status and Recent Extreme Events. IEEE Power Energy Mag. 2015, 13, 67-77. [CrossRef]

3. Chen, H.; Xuan, P.; Wang, Y.; Tan, K.; Jin, X. Key Technologies for Integration of Multitype Renewable Energy Sources-Research on Multi-Timeframe Robust Scheduling/Dispatch. IEEE Trans. Smart Grid 2016, 7, 471-480. [CrossRef]

4. Kumar, R.; Agarwala, A.K. Renewable energy technology diffusion to mitigate climate change impact. Int. J. Environ. Sci. Dev. Monit. 2013, 4, 52-57.

5. Corsatea, T.D.; Giaccaria, S.; Covrig, C.-F.; Zaccarelli, N.; Ardelean, M. RES diffusion and R\&D investments in the flexibilisation of the European electricity networks. Renew. Sustain. Energy Rev. 2016, 55, 1069-1082. 
6. Breyer, C.; Koskinen, O.; Blechinger, P. Profitable climate change mitigation: The case of greenhouse gas emission reduction benefits enabled by solar photovoltaic systems. Renew. Sustain. Energy Rev. 2015, 49, 610-628. [CrossRef]

7. Abbasi, S.A.; Tabassum-Abbasi; Abbasi, T. Impact of wind-energy generation on climate: A rising spectre. Renew. Sustain. Energy Rev. 2016, 59, 1591-1598. [CrossRef]

8. Longo, M.; Roscia, M.; Lazaroiu, G.C.; Pagano, M. Analysis of sustainable and competitive energy system. In Proceedings of the 3rd International Conference on Renewable Energy Research and Applications (ICRERA 2014), Milwaukee, WI, USA, 19-22 October 2014; pp. 80-86.

9. Dowds, J.; Hines, P.; Ryan, T.; Buchanan, W.; Kirby, E.; Apt, J.; Jaramillo, P. A review of large-scale wind integration studies. Renew. Sustain. Energy Rev. 2015, 49, 768-794. [CrossRef]

10. Thale, S.S.; Wandhare, R.G.; Agarwal, V. A Novel Reconfigurable Microgrid Architecture with Renewable Energy Sources and Storage. IEEE Trans. Ind. Appl. 2015, 51, 1805-1816. [CrossRef]

11. Monforti, F.; Gaetani, M.; Vignati, E. How synchronous is wind energy production among European countries? Renew. Sustain. Energy Rev. 2016, 59, 1622-1638. [CrossRef]

12. Malinowski, M.; Milczarek, A.; Kot, R.; Goryca, Z.; Szuster, J.T. Optimized Energy-Conversion Systems for Small Wind Turbines: Renewable energy sources in modern distributed power generation systems. IEEE Power Electron. Mag. 2015, 2, 16-30. [CrossRef]

13. Hajipour, E.; Bozorg, M.; Fotuhi-Firuzabad, M. Stochastic Capacity Expansion Planning of Remote Microgrids with Wind Farms and Energy Storage. IEEE Trans. Sustain. Energy 2015, 6, 491-498. [CrossRef]

14. Ozgener, O.; Ozgener, L. Exergy and reliability analysis of wind turbine systems: A case study Review. Renew. Sustain. Energy Rev. 2007, 11, 1811-1826. [CrossRef]

15. Neeraj, G. A review on the inclusion of wind generation in power system studies. Renew. Sustain. Energy Rev. 2016, 59, 530-543.

16. Wang, X.; Wei, X.; Meng, Y. Experiment on Grid-Connection Process of Wind Turbines in Fractional Frequency Wind Power System. IEEE Trans. Energy Convers. 2015, 30, 22-31. [CrossRef]

17. Zeng, P.; Wen, J. Foreword for the special section on sustainable power network planning. CSEE J. Power Energy Syst. 2016, 2, 1-2. [CrossRef]

18. Gazzetta ufficiale dell'Unione europea. Direttiva 2009/28/CE Del Parlamento Europeo E Del Consiglio, del 23 Aprile 2009, Sulla Promozione Dell'uso Dell'energia da Fonti Rinnovabili, Recante Modifica e Successiva Abrogazione Delle Direttive 2001/77/CE e 2003/30/CE; Gazzetta Ufficiale: Roman, Italy, 2009; pp. 16-62.

19. Kim, Y.-S.; Hwang, C.-S.; Kim, E.-S.; Cho, C. State of Charge-Based Active Power Sharing Method in a Standalone Microgrid with High Penetration Level of Renewable Energy Sources. Energies 2016, 9, 480. [CrossRef]

20. Brenna, M.; Foiadelli, F.; Longo, M.; Zaninelli, D. Power quality improvement in primary distribution grids through vehicle-to-grid technologies. In Proceedings of the 2014 IEEE International Electric Vehicle Conference (IEVC 2014), Florence, Italy, 17-19 December 2014.

21. Mehrasa, M.; Pouresmaeil, E.; Zabihi, S.; Caballero, J.C.T.; Catalão, J.P.S. A Novel Modulation Function-Based Control of Modular Multilevel Converters for High Voltage Direct Current Transmission Systems. Energies 2016, 9, 867. [CrossRef]

22. Xue, S.; Yang, J.; Chen, Y.; Wang, C.; Shi, Z.; Cui, M.; Li, B. The Applicability of Traditional Protection Methods to Lines Emanating from VSC-HVDC Interconnectors and a Novel Protection Principle. Energies 2016, 9, 400. [CrossRef]

23. Aragues-Penalba, M.; Rimez, J.; Beerten, J.; van Hertem, D.; Gomis-Bellmunt, O. Secure and optimal operation of hybrid AC/DC grids with large penetration of offshore wind. In Proceedings of the 11th IET International Conference on AC and DC Power Transmission, Birmingham, UK, 10-12 February 2015.

24. Kies, A.; Schyska, B.U.; von Bremen, L. Curtailment in a Highly Renewable Power System and Its Effect on Capacity Factors. Energies 2016, 9, 510. [CrossRef]

25. Denholm, P. Energy storage to reduce renewable energy curtailment. In Proceedings of the 2012 IEEE Power and Energy Society General Meeting, San Diego, CA, USA, 22-26 July 2012; pp. 1-4.

26. Lew, D.; Bird, L.; Milligan, M.; Speer, B.; Wang, X.; Carlini, E.M.; Estanqueiro, A.; Flynn, D.; Gomez-lazaro, E.; Menemenlis, N.; et al. Wind and Solar Curtailment Preprint. In Proceedings of the International Workshop on Large Scale Integration of Wind Power into Power Systems as Well as on Transmission Networks for Offshore Wind Power Plants, London, UK, 22-24 October 2013. 
27. O'Malley, M. Grid Flexibility and Research Challenges to Enhance the Integration of Variable Renewable Energy Sources; Stanford Precourt Institute for Energy: Stanford, CA, USA, 2013.

28. Revuelta, J.; Fernández, J.C.; Fernández, J.L. Large scale integration of renewable energy sources in the Spanish power system. Curtailment and market issues. In Proceedings of the 2011 8th International Conference on the European Energy Market (EEM), Zagreb, Croatia, 25-27 May 2011; pp. 413-418.

29. GSE-Atlavento. Available online: http://atlaimpianti.gse.it/atlavento/ (accessed on 1 November 2016).

30. Software PLEXOS. Available online: http:/ / www.plexus.com/ (accessed on 1 November 2016).

31. Gullìa, F. The impact of intermittently renewable energy on Italian wholesale electricity prices: Additional benefits or additional costs? Energy Policy 2015, 83, 123-137. [CrossRef]

32. Black \& Vetch Holding Company. Cost and Performance data for Power Generation Technologies; Black \& Vetch Holding Company: Kansas City, MO, USA, 2012.

33. World Bank Commodity Price Data (Pink Sheet), May 2015-knoema.com. Available online: http: //knoema.com/WBCPD2015Apr/world-bank-commodity-price-data-pink-sheet-may-2015 (accessed on 1 November 2016).

34. Terna. Rapporto Mensile sul Sistema Elettrico-Consuntivo Dicembre 2014; Terna: Roma, Italy, 2014.

35. Korompili, A.; Wu, Q.; Zhao, H. Review of VSC HVDC connection for offshore wind power integration. Renew. Sustain. Energy Rev. 2016, 59, 1405-1414. [CrossRef]

36. Kalair, A.; Abas, N.; Khan, N. Comparative study of HVAC and HVDC transmission systems. Renew. Sustain. Energy Rev. 2016, 59, 1653-1675. [CrossRef]

37. Nolasco, J.F.; Jardini, J.A.; Graham, J.F. Impacts of HVDC Lines on the Economics of HVDC Projects; Task Force; IEEE Power \& Energy Society: Piscataway, NJ, USA, 2009.

38. Marcantonini, C.; Valero, V. Renewable Energy Incentives and $\mathrm{CO}_{2}$ Abatement in Italy, European University Institute Robert Schuman Centre for Advanced Studies, Florence School of Regulation Climate; EUI Working Paper RSCAS2015/20; European University Institute: Florence, Italy, 2015.

39. Benedetti, L. Italian Experience in Deploying Renewable Energy. RES4MED DAYS "A Step Change in the Deployment of RE and EE Solutions in the Mediterranean"; Renewables Energy Solutions for the Mediterranean: Rabat, Morocco, 2014.

40. Osborn, D. Potential value of HVDC overlays to provide a more reliable and economical power system. In Proceedings of the 2011 IEEE Power and Energy Society General Meeting, Detroit, MI, USA, 24-29 July 2011.

41. Wang, S.; Guo, J.; Li, C.; Balasubramaniam, S.; Zheng, R.; Liang, J. Coordination of DC power flow controllers and AC/DC converters on optimising the delivery of wind power. IET Renew. Power Gener. 2016, 10, 815-823. [CrossRef]

(C) 2017 by the authors; licensee MDPI, Basel, Switzerland. This article is an open access article distributed under the terms and conditions of the Creative Commons Attribution (CC BY) license (http://creativecommons.org/licenses/by/4.0/). 